\title{
Development of a remote monitoring system using a portable phone for manufacturing support systems
}

\author{
Toshiaki KIMURA ${ }^{1)}$, Yuichi KANDA ${ }^{2)}$ \\ 1) Japan Society for the Promotion of Machine Industry, 1-1 - 12, achiman - Cho, \\ Higashikurume - City Tokyo, 203 -0042, Japan \\ Email: kimura@tri.jspmi.or.jp \\ 2) Toyo University, Faculty of Engineering, 2100 Kujirai, Kawagoe - City, Saitama, 350 - \\ 8585, Japan \\ Email: cimkanda@toyonet.toyo.ac.jp
}

\begin{abstract}
Manufacturing systems that can be adapted to the fluctuations of the number of orders and the kind of products for smaller enterprises are required. These systems are based on the premise that manufacturing products in small quantities by manual operations is done in the daytime and large quantities are manufactured at night using automated systems. But recent sharp fluctuations in the number and variety of orders make the continuation of the present way of manufacturing difficult.

On the other hand, open-oriented information technologies such as the Internet and open controllers as open NCs (Numerical Controllers) are available for large-scale manufacturing systems today. However, in the smaller enterprises, they seldom adopt such technologies because they do not have the IT (Information Technologies) infrastructure and there are also cost considerations. Therefore, this research discusses a manufacturing support system, which takes into account manual-operated processes coexisting with automated processes for smaller enterprises. This becomes possible by using the open-oriented information technologies.

In this paper, a concept of a planned manufacturing support system is proposed. The development of a remote monitoring system using a portable phone for collaborative operations between the factory side and the remote side as one component of the manufacturing support system has been researched. The system and evaluation of results of the remote monitoring system by a test operation using a load balancing system with remote control functions previously developed are described.
\end{abstract}

\section{Keywords}

Manufacturing Support Systems, Remote Monitoring Systems, Remote Control Systems, Collaborative Operations, Information Technologies, Open Controllers.

\section{INTRODUCTION}

There are many cases of large-scale enterprises using automated manufacturing systems and a shift work system in factories for producing a limited variety of products in large quantities with non-fluctuations of the number of orders. The 
smaller enterprises, which are subcontracted by the large-scale enterprises, often deal with production in which the number of orders and the kind of products fluctuate greatly.

The present conditions of production of these large-scale enterprises and the smaller enterprises are shown in the Figure 1. Therefore, most manufacturing systems for the smaller enterprises are based on the premise that manufacturing products in small quantities by manual operations is done in the daytime and large quantities are manufactured at night using automated systems. But recent sharp fluctuations in the number of orders make the continuation of the present way of manufacturing for the smaller enterprises difficult.

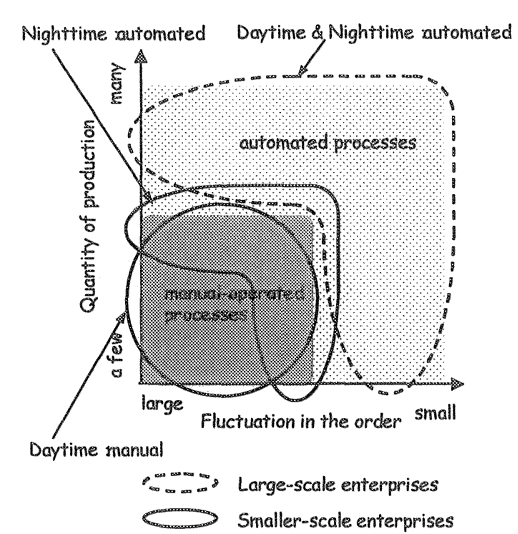

Figure 1 Actual conditions of the production

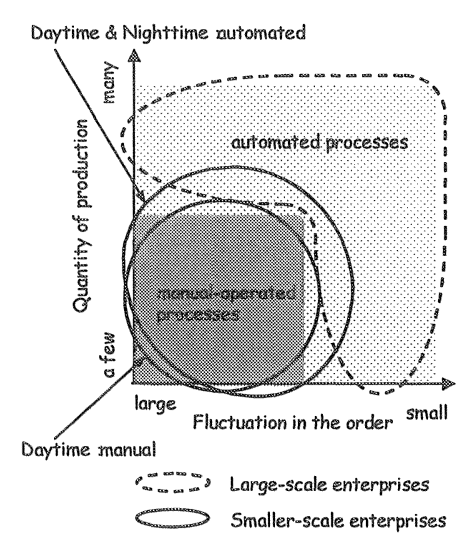

Figure 2 Proposed conditions of the production

On the other hand, open-oriented information technologies such as the Internet and open controllers are available for manufacturing systems today. However, most application systems using the information technologies are targeting the large-scale manufacturing systems in factories of large-scale enterprises. Those application systems cannot always be used in the smaller enterprises.

Therefore, the goal of this research is to construct a manufacturing support system which takes into consideration manual-operated processes coexisting with automated processes for smaller enterprises as is shown in Figure 2. This becomes possible by using open-oriented information technologies.

The concept of a planned manufacturing support system and development of a remote monitoring system using portable phones for collaborative operations between the factory side and the remote side is explained. Finally, evaluation results of the remote monitoring system by a test operation using a load balancing system with remote control function which has been developed is also described. 


\section{CONCEPT OF THE MANUFACTURING SUPPORT SYSTEM FOR SMALLER ENTERPRISES}

The outline of factories for the smaller enterprises that are the target of this research and a concept of the manufacturing support system are presented in this section. The factories for the smaller enterprises usually consist of a few machine tools, material handling components and robots. It is presumed that the processing of machine parts is the main activity of those factories. Production plans are dependent on job-order production rather than continuous order information. Therefore, high flexibility machine tools such as M/Cs (Machining Centres) will be used in the factories of the smaller enterprises.

A basic concept of the manufacturing support system for such factories of the smaller enterprises can be adapted to the following three cases regardless of the daytime or night-time production. The first case is that workers operate all machine tools setting up all tools, jigs and materials manually. The second case is that all machine tools and material handling machines are operated automatically using tools, jigs and machines, which have been set up in advance. The last case is a system coexisting or combined with the first case and the second case.

Configuration of the material handling system such as gantry robot type transfer machines of the manufacturing support system was considered because it often fits the above conditions and avoids intervening in the workers' area [1]. Also, the manufacturing support system includes communication environments connected with multi-vendor's machine tools, process management systems and a remote monitoring system using information technologies such as portable phones and the Internet. Furthermore, the manufacturing support system can be adapted to a fluctuation in load balancing caused by trouble or the malfunction of devices such as machine tools resulting in delays of the work in the manufacturing system.

The system we propose maintains a well-balanced workload by operating the production schedule file of the manufacturing system in consideration of decisions by an operator with the remote control function using the Internet. This function reduces the need for the operator to physically go to the factory during the unmanned night operations.

This manufacturing support system contains an after sales support interenterprise collaboration system which provides not only maintenance services for the factories but also consulting services with inter-enterprise collaboration by engineering companies and machine tool vendors for a manufacturing system consisting of multi-vendor's machine tools. This after sales support system has been labelled "After Sales Support Inter-enterprise collaboration System using information Technologies" or ASSIST [2]. The basic concept of the manufacturing support system that has these functions and these structures is shown in the Figure 3 [3]. 


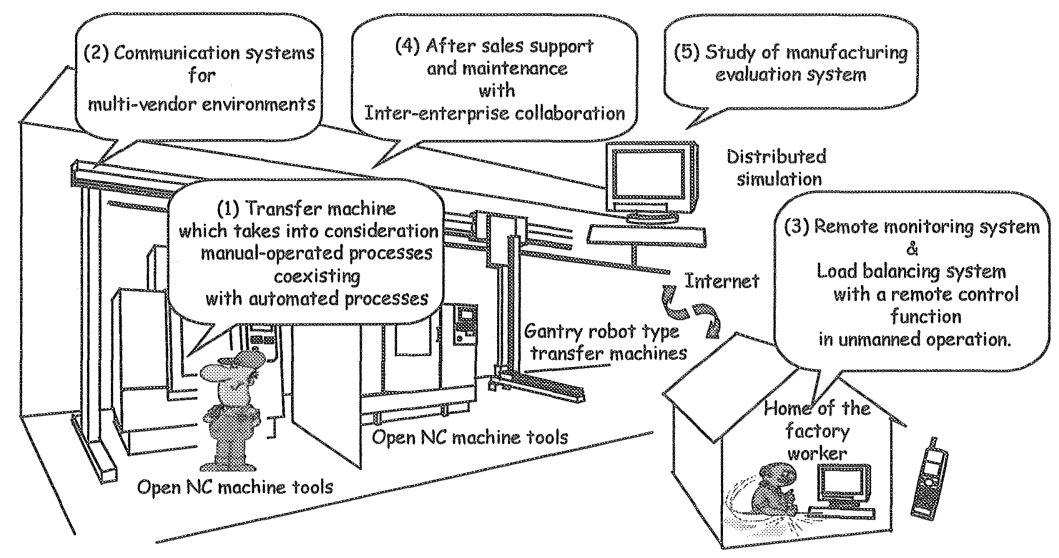

Figure 3 Basic concept of the manufacturing support system

\section{DEVELOPMENT OF THE REMOTE MONITORING SYSTEM USING PORTABLE PHONES}

\section{Outline of the remote monitoring system}

The aim of the development of the remote monitoring system is to accomplish functions such as the monitoring of the operating conditions for multi-vendor's machine tools, the whole manufacturing system, the production status by product name and the inspection results of the finished products. This monitoring also includes notification when production delays occur and/or equipment troubles occur and notification for a specific process to be completed by manufacturing system operators during a collaborative operation between the factory side and the remote side.

The terminals of this system are cellular telephones including the PHS (Personal Handy-phone System) for portability. Because users don't always have the portable telephone which has a Web browser function like the I-mode of NTT DoCoMo, Inc. [4], the basic communication method of the system is by Email limited by registered Email addresses.

\section{System configuration of the remote monitoring system}

Configuration of the remote monitoring system is shown in Figure 4. The system consists of the factory side and the remote side. The Web/Email server on the intranet that gathers the operation data from the server of multi-vendor process management servers such as MES (Manufacturing System Execution) is prepared on the factory side [5, 6]. Data for e-business collaboration is sent to a Web server on the extranet, which is called the DMZ or (Demilitarized Zone) level network on the 
factory side. The portable phones at the remote side can exchange data with the factory side using Email and/or HTTP (Hyper Text Transfer Protocol) through the Internet.

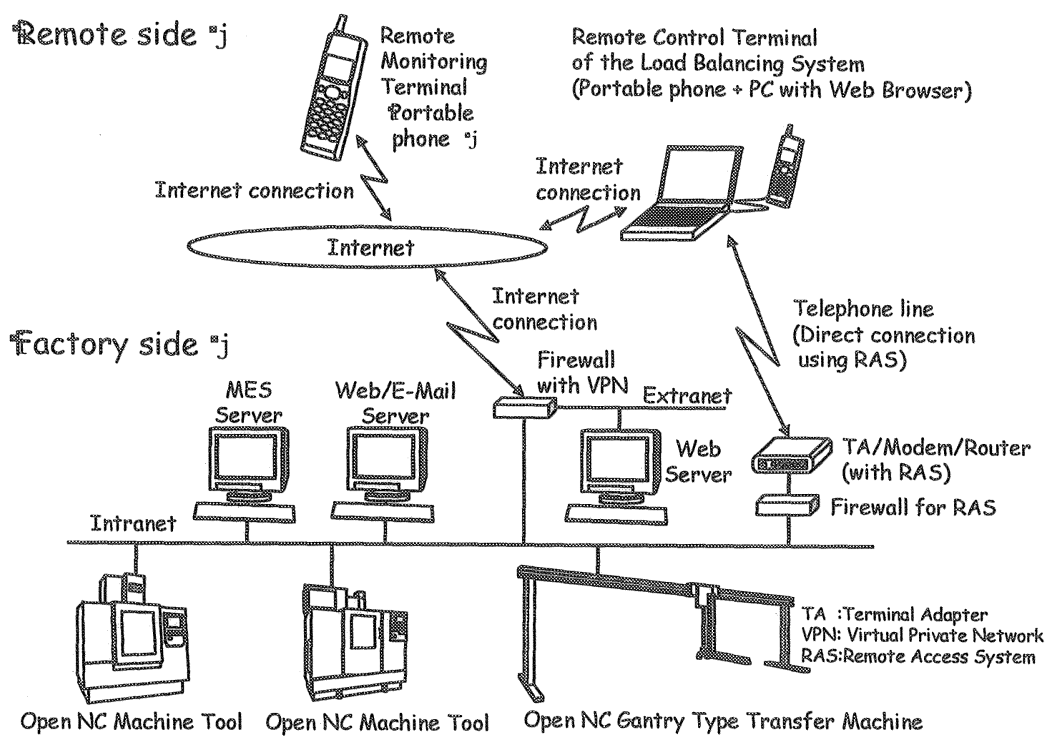

Figure 4 System configuration of the remote monitoring system

\section{Functions of the remote monitoring system}

The functions of the monitoring system are as follows.

1. Confirmation of the production status by product name

2. Confirmation of the production status by lot number

3. Notification when production delays occur

4. Notification when equipment troubles occur

5. Notification for a specific process to be completed

6. Confirmation of inspection results of the finished product and transmission of an image of the completed product (this last step is currently being developed).

Confirmation of the production status by product name, means that after sending Email with the characters "P: " + "product name" to a subject from the portable phone to the Web/Email server on the intranet, the portable phone can receive confirmation of the production status by Email. If one or more lots exist for the product, these lot numbers are described in the contents of the Email reply. After getting these lot numbers, "Confirmation of the production status by lot number" function becomes available.

Confirmation of the production status by lot number is the function where Email with characters "L: " + "lot number" are sent to a subject from the portable phone to 
the Web/Email server on the intranet. The portable phone can receive a confirmation of the production status of the product by lot number through Email.

Notification when production delays occur is the function where the Web/Email server on the intranet of the factory sends the Email to the portable phone when processes don't start if actual time passes the expected start schedule time.

Notification when equipment troubles occur is the function where the $\mathrm{Web} /$ Email server on the intranet of the factory sends the notification Email to the portable phone indicating equipment problems.

Notification for a specific process to be completed is as follows. If there is a product with more than one process and Email including product name or lot number is transmitted in advance from portable phone to Web/Email server on the intranet, the portable phone can receive a reply by Email when the product or the lot is completed.

Confirmation of inspection results of the finished product and transmission of an image of the completed product" indicates that image data and inspection data of products are uploaded to the Web/Email server of the intranet for every completed lot. Selected data from the Web/Email server for e-business collaboration such as sales activities is then sent to a Web server on the extranet. The portable phone and/or the remote side PC (Personal Computer) as the remote control terminal of the load balancing system can access this data from the Web server on the extranet.

Examples of these functions are shown in Figure 5 and Figure 6. Figure 5 is an example of "Confirmation of the production status by the product name" and Figure 6 is an example of "Confirmation of inspection results of the finished products and transmission of an image of the completed product." The step shown in Figure 6 is currently being developed.

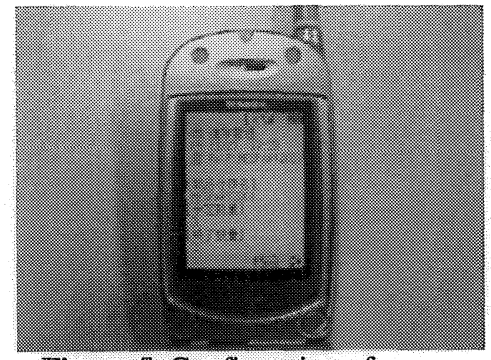

Figure 5 Confirmation of the production status by the product name

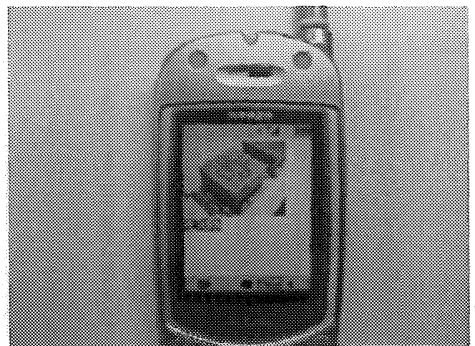

Figure 6 Transmission of an image of the product 


\title{
EVALUATION OF THE REMOTE MONITORING SYSTEMI USING A PORTABLE PHONE
}

\author{
Overview of the load balancing system with remote control \\ function
}

A test operation of the remote monitoring system was evaluated using a load balancing system with a remote control function previously developed.

An outline of the load balancing system is as follows. To adapt to fluctuations in load balancing due to device problems and/or work delays during unmanned operation, the load balancing system with a remote control function using Internet and/or telecommunication was developed. As for this remote control method, an operator at the remote place side does not control the devices directly when adapting to fluctuations in load balancing caused by trouble from devices such as machine tools or delays of work in the manufacturing system. The system creates the workload balancing uniformity with the remote control by operating the production schedule file of the manufacturing system. This method allows the load balancing system to take the operator's decisions into consideration.

The load balancing system has an additional PC, which can be connected to the Internet and/or telecommunications for connecting with the factory side. A security system such as VPN (Virtual Private Network), and access control to particular controllers of the factory by a firewall of the factory's system are available when communicating with the Internet. Similar access control to particular controllers of the factory by a firewall is also available for communication through the telecommunication means. Here the operation sequence flow of the system is presented.

1. The production schedule file of the manufacturing system is located in the MES server on the intranet of the factory.

2. Each process of the products in the production schedule file can be set using three types of priority flags such as when the processing machine tool is limited for a particular process (Priority value 1), the processing machine tools are selectable (Priority value 2) or when machine tools are not selected (Priority value 3$)$.

3. The MES sever on the intranet of the factory indicates the processing execution to the machine tools in accordance with the priority flags of each process of the products in the production schedule file.

4. However, when trouble with devices such as machine tools or work delays occur in the manufacturing system and processing by machine tools that are described by the priority flags cannot be done, Web/Email server on the intranet transmits an Email to the portable phone of an operator on the remote place side to inform the operator about processes which cannot be executed. The functions of the monitoring system "Notification when production delays occur" and "Notification when equipment troubles occur" are used in this case.

5. Then, the operator connects to the Web/Email server on the intranet of the factory side using the Internet or telecommunication from the remote place side. The operator by Web operation then decides and assigns the processes to 
functioning machine tools that are unassigned. The easing of the workload is then realized by this process.

\section{Evaluation results of the remote monitoring system}

The test system configuration is shown in Figure 7. The factory consists of two multi-vendor's open NC machine tools (A \& B) and one open NC gantry robot type transfer machine. These multi-vendor's machine tools and the transfer machine are integrated with the OpenMES, which is one of the commercial products of MES from IBM Japan, Ltd.. Communication environments of the factory for connecting between the intranet and the remote side PC are an Internet connection with VPN and/or RAS (Remote Access System) when using telecommunications. A portable phone for remote monitoring and a client PC with a Web browser for remote control are prepared on the remote side.

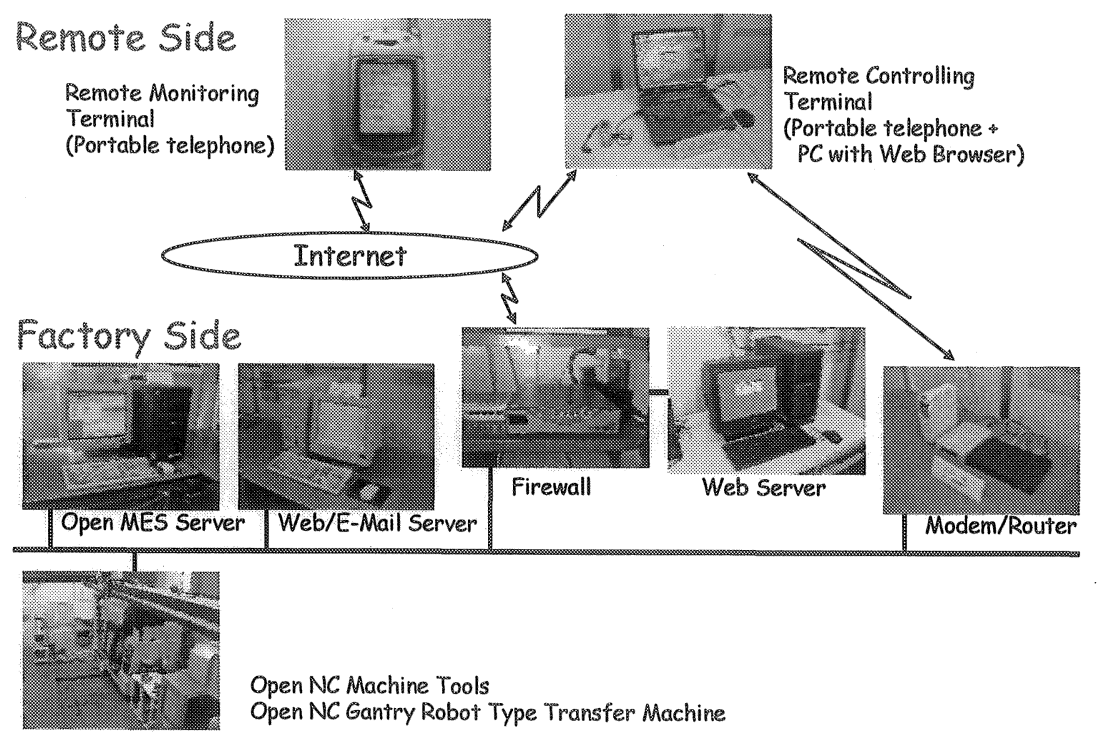

Figure 7 System configuration of the test operation

In the test operation, the production schedule file contained 10 of the product "MESPART3-001". "MESPART3-001" has only one process whose priority values are 1 for machine tool $\mathrm{B}$ and 2 for machine tool $\mathrm{A}$.

Normally, the system would select machine tool B after starting the system. Pushing the emergency button created a simulated error of machine tool B. A few seconds after pushing the emergency button, the portable phone of the remote monitoring system receives Email notification that equipment trouble has occurred in machine tool B.

After receiving the Email, the remote operator connects the remote $\mathrm{PC}$ to the Web/Email server on the intranet of factory side using the Internet or telecommunications. The operator then changes the allotment of machine tools from 
$\mathrm{B}$ to $\mathrm{A}$ for the process by remote control using the Web browser. The product MESPART3-001 will continue to be processed by machine tool A.

The image of this remote control operation using the Web browser is shown in Figure 8. In the Figure, the process "00000008" is stopped by an error of machine tool B (KAKOU02). However, the process is continued by changing the allotment of machine tool B to machine tool A (KAKOU01) using the remote operation.

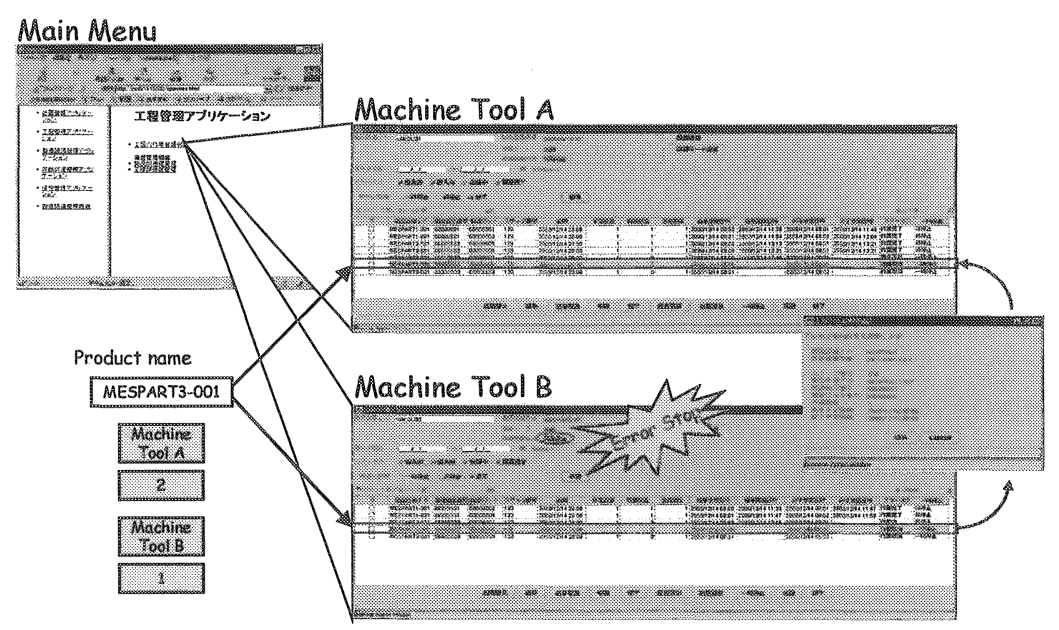

Figure 8 Web operation of the load balancing system

"Confirmation of the production status by product name" and "Confirmation of the production status by lot number" functions were also evaluated during the test operation of the load balancing system. The results of the evaluation confirmed that these functions were executed correctly.

According to the results of these test operations, the verification and successful application of the "Confirmation of the production status by product name", "Confirmation of the production status by lot number", "Notification when production delays occur" and "Notification when equipment troubles occur" functions of the monitoring system were completed. It was confirmed by this test operation that a remote monitoring system using a portable phone could be set up as one component of the manufacturing support system for collaborative operations using a load balancing system with remote control function.

"Notification for a specific process to be completed" and "Confirmation of inspection results of the finished products and transmission of an image of the completed product" functions will be evaluated for the remote monitoring system in future tests. The development of the manufacturing support system for smaller enterprises will then be completed 


\section{CONCLUSIONS}

This paper presents a concept of a planned manufacturing support system. Development results of the remote monitoring system using a portable phone for collaborative operations between the factory side and remote side as one of the components of the system were described. Finally, the evaluation results of the remote monitoring system by a test operation using a load balancing system with remote control functions were carried out and the results explained.

This paper also describes the type of smaller enterprise factories that are the target of this research and an outline of the manufacturing support system, showing the remote monitoring system, configuration of the system and functions and development of the remote monitoring system using a portable phone. Introduction of the load balancing system with remote control functions and evaluation results of a test operation of the remote monitoring system using a load balancing system with remote control functions were also presented. This confirmed that a remote monitoring system using a portable phone could be realized as one component of the manufacturing support system for collaborative operations between the factory side and the remote side by test operations using a load balancing system with remote control function.

According to the results of these test operations, development of "Confirmation of the production status by product name", "Confirmation of the production status by lot number", "Notification when production delays occur" and "Notification when equipment troubles occur" functions of the remote monitoring system have been successfully completed. After sales support for an inter-enterprise collaboration system using information technologies and multi-media remote monitoring systems containing 3-D models, are components of the manufacturing support system that need to be developed. When these are added, the development of the manufacturing support system for smaller enterprises will be completed. As a result of this research it has become apparent that small enterprises with limited resources can still take advantage of the unique and powerful capabilities of IT tools.

\section{ACIKNOWLEDGEMENTS}

This research is a part of the "Study on Manufacturing System using OpenOriented Information Technologies" which is a research project of Japan Society of the Promotion of Machine Industry (JSPMI). The project is supported by funding from the Keirin Association of Japan.

\section{REFERENCES}

[1] T.Kimura, H.Hibino, S.Ueno, A study of manufacturing system for the smaller enterprises using information technologies, 1st report, A development of Open NC Gantry Robot Transfer Machines, Japan Society for Precision Engineering Autumn Meeting 1999, pp.62 
[2] T.Kimura, M.Tsuchidate, F.Kasai, M.Asamori, Y.Kamio and Y.Kanda, Development of an After Sales Support Inter-enterprise Collaboration System using Information Technologies, Japan Society of Mechanical Engineers Annual Meeting 2001, vol. III, pp.325 - 326

[3] T.Kimura, Y.Kanda, Development of manufacturing support system using OpenOriented information technologies, 7th International Conference on Production Engineering, Design and Control, vol. 1, 2001, pp.201 - 208

[4] http: //www.nttdocomo.com/

[5] http: //mesa.org/

[6] IBM Japan, Ltd., OpenMES Specification Ver.1.0 Draft Alpha, May 25.1999 